\title{
Introduction to Special Issue "Shallow Water Mapping in Coastal Environments: Recent Research, Current Technologies, and Multi-modal Approaches"
}

\author{
Monique LaFrance Bartley ${ }^{1,2}$ (1) $\cdot$ Mark Borrelli ${ }^{3,4}$
}

Received: 24 January 2022 / Revised: 24 January 2022 / Accepted: 25 January 2022 / Published online: 28 February 2022

This is a U.S. government work and not under copyright protection in the U.S.; foreign copyright protection may apply 2022

\section{Introduction}

Coastal and nearshore ecosystems are among the most dynamic environments on earth and their inherent complexity is further enhanced by climate change and human activity. The value to society provided by myriad and vital ecosystem services warrants significant increases in public awareness, scientific investigation, and associated funding. An interdisciplinary understanding of ecosystem structure and function across various spatial and temporal scales is critical for policy makers, government agencies, and other stakeholders. These groups must be well-informed to develop and implement scientifically sound strategies that maintain a balance between the protection and human use of coastal and nearshore areas. Maps and associated geospatial data of coastal and submerged lands provide essential information, including topography and bathymetry, geomorphology, and composition and distribution of habitats. This information is necessary for guiding management and planning decisions regarding natural, cultural, and historical resources; facilities and infrastructure; and recreational uses and public safety. Optimally, mapping is multidisciplinary and

Communicated by Paul A. Montagna

Monique LaFrance Bartley

monique_lafrancebartley@nps.gov

1 Present Address: National Park Service, Water Resources Division, 1201 Oakridge Drive, Fort Collins 80525, CO, USA

2 Graduate School of Oceanography, University of Rhode Island, 215 South Ferry Road, Narragansett, RI 02882, USA

3 Department of Marine Geology Center for Coastal Studies, Provincetown, MA 02657, USA

4 Coastal Processes and Ecosystems Laboratory (CaPE Lab), School for the Environment, University of Massachusetts, Boston, MA 02125, USA multipurpose, utilized to understand conditions and monitor change; support post-incident damage and resource vulnerability assessments; and serve as key inputs for modeling studies (e.g., hydrodynamics, sediment budget and transport; sea-level rise, storm impacts, outcome of specific management actions, species distribution; trophic interactions). In these ways, mapping data can provide a more holistic view of ecosystems and assets, allow for better understanding of current and anticipated future change, and support coastal resiliency and adaptation efforts.

Data collection within the coastal and nearshore zones has historically been logistically challenging and costly due to shallow water depths and other hazards to navigation, tidal restrictions, turbidity, wave activity, recreational users, etc. Recent technological advances in remote sensing and survey platforms have reduced logistical constraints and expanded opportunities to map coastal areas. Furthermore, developments in data classification schemas, movement toward interdisciplinary research, and the agreed upon need for synoptic-scale studies have facilitated consistency and comparability of results across projects and field settings. While beneficial, this rapid scientific progress can also cause increased lag between active research and management actions. To close this gap, further emphasis needs to be placed on strengthening relationships between scientists and end users.

The ability to leverage new technologies and research to map coastal and nearshore waters efficiently and effectively is increasing in importance. The growing recognition that mapping provides critical information has led to the initiation of regional and global mapping efforts. For example, after Hurricane Sandy in 2012 the United States National Park Service funded studies in four northeast region coastal parks by different groups with the primary objectives to develop benthic habitat maps to inform management and define suitable methods for mapping in shallow waters (LaFrance Bartley et al. 2019). Larger ongoing initiatives 
to map the world's oceans include Seabed 2030 (Mayer et al. 2018) and National Strategy for Mapping, Exploring, and Characterizing the United States Exclusive Economic Zone (Ocean Policy Committee 2020). Similarly, Lakebed 2030 (Van Sumeren 2020) is an ongoing initiative to map the Great Lakes.

The manuscripts within this special issue, entitled, Shallow water mapping in coastal environments: Recent research, current technologies and multi-modal approaches, find commonality around the central question, "Which developing, new or traditional remote sensing technologies and methods are best suited to develop maps in coastal and nearshore settings that will allow investigators to study these critical resources and processes, and also allow for the needs of managers and regulators to be addressed?" The manuscripts document recent and ongoing research across multiple disciplines that discuss traditional and cutting-edge techniques and methods; the efficacy of various mapping approaches in capturing coastal and nearshore resources and processes; and applied research to support real-world management needs. The manuscripts presented also cover a broad geographical distribution, including the east, west, and gulf coasts of the USA, Portugal, and Australia. This special issue focused on shallow water mapping is a timely, substantive, and important collection of papers in this rapidly evolving, interdisciplinary area of study.
Acknowledgements The guest editors thank the authors who contributed manuscripts to this special issue. We also wish to acknowledge the valuable contributions of the presenters within our dedicated sessions at the 24th, 25th, and 26th biennial Coastal and Estuarine Research Federation (CERF) Conferences. It was the enthusiastic feedback from these sessions that provided the impetus for this special issue.

\section{References}

LaFrance Bartley, M., L. Curdts, and S. Stevens. 2019. Procedures and criteria for evaluating benthic mapping data: a northeast coastal and barrier network methods document. Natural Resource Report NPS/NCBN/NRR - 2019/2050. National Park Service, Fort Collins, Colorado. https://irma.nps.gov/DataStore/Reference/Profile/ 226781884. Accessed 15 Jan 2022.

Mayer, L., M. Jakobsson, G. Allen, B. Dorschel, R. Falconer, V. Ferrini, G. Lamarche, H. Snaith, and P. Weatherall. 2018. The Nippon Foundation-GEBCO Seabed 2030 Project: the quest to see the world's oceans completely mapped by 2030 . Geosciences 8 (2). https://doi.org/10.3390/geosciences 8020063.

Ocean Policy Committee. 2020. National strategy for mapping, exploring, and characterizing the United States exclusive economic zone. Rep prep by the Ocean Sciences and Technology Subcommittee 25. https://trumpwhitehouse.archives.gov/wp-content/uploads/ 2020/01/20200611-FINAL-STRATEGY-NOMEC-Sec.-2.pdf. Accessed 15 Jan 2022.

Van Sumeren, H. 2020. Lakebed 2030: A vision of comprehensive Great Lakes mapping coverage. Marine Technology Society Journal 54 (3): 4-5. https://doi.org/10.4031/MTSJ.54.3.7. 